\title{
PERANCANGAN MAIL CLIENT MENGGUNAKAN MEKANISME CREATE FOLDER OTOMATIS
}

\author{
Anggaini Kusumaningrum ${ }^{1}$, Astika Ayuningtyas ${ }^{2}$, Lely Delvia Sipayung ${ }^{3}$ \\ Program Studi Teknik Informatika \\ Sekolah Tinggi Teknologi Adisutjipto \\ anggraini@stta.ac.id ${ }^{1}$, astika@stta.ac.id ${ }^{2}$, Lely2sipayung@gmail.com ${ }^{3}$
}

\begin{abstract}
The development of computer technology and telecommunications right now has changed the way society communicates. The technology used to communicate exists since the first Internet presence, that is to say by using the electronic mail. Email is a technology that allows everyone to communicate by sending messages or files. As with other ways that can be used to read and send emails, use the email client application. Email client is an application installed on a computer device used to access the email account on an email server, the email client does not need to use a browser application. But as long as this classification on email is still done manually on the part where the file storage download. To resolve the issue ranking of emails can be done automatically according to the name of the subject of e-mail, messages or files that are entered on the e-mail client of the application can then be downloaded and the data to download are stored in the folder that corresponds to the name of the subject e-mail, so that a message or file will be stored in a folder, it gives the convenience classification for mail client application mail user electronic with the number of messages or files that are much more consistent with the existing keywords in the subject of the email. This email client application can create folders automatically when downloading messages. Then, the downloaded file will be stored in the folder corresponding to the name of the subject. The file extension downloaded *.ml, the file can be opened via the mail client application. The mail client application can run on Windows and Linux operating systems.
\end{abstract}

Keywords : Mail Client application, Create automatic folder, Save downloaded file automatically.

\section{Pendahuluan}

Perkembangan teknologi komputer dan teknologi telekomunikasi pada saat ini telah mengubah cara masyarakat dalam berkomunikasi. Sampai sejauh ini perkembangan teknologi informasi sangat pesat. Dalam perkembangan informasi yang paling banyak didapatkan oleh masyarakat umum adalah melalui internet. Dengan memanfaatkan jaringan internet, pertukaran informasi dan data tidak menjadi hal yang sulit. Teknologi yang digunakan untuk berkomunikasi telah ada sejak internet pertama kali hadir yaitu dengan menggunakan email. Email merupakan teknologi yang memungkinkan setiap orang untuk berkomunikasi dengan mengirimkan pesan atau mengirimkan berkas.

Adapun cara lain yang dapat digunakan untuk membaca dan mengirim email yaitu dengan menggunakan aplikasi Email Client. Aplikasi Email Client yaitu sebuah aplikasi yang diinstal pada sebuah perangkat komputer yang digunakan untuk mengakses akun Email pada sebuah Server Email, dengan aplikasi email client tidak perlu menggunakan aplikasi browser. Beberapa contoh aplikasi Email Client seperti Outlook Express, Microsoft Outlook, Thunderbird, dan Windows Mail. Selama ini pengklasifikasian pada email masih dilakukan secara manual [1]. Pengklasifikasian email dapat dilakukan secara otomatis berdasarkan subject, untuk pesan atau berkas yang masuk pada email tersebut kemudian akan diunduh dan data yang akan diunduh disimpan pada folder yang sesuai dengan nama subject pesan atau berkas tersebut. Aplikasi ini 
lebih efektif penggunaannya jika mempunyai pesan atau berkas yang masuk dengan jumlah yang banyak dan meimliki nama subject yang sama, sehingga pesan atau berkas tersebut akan tersimpan dalam satu folder, sehingga memberi kemudahan kepada pengguna aplikasi mail client untuk pengklasifikasian email dengan jumlah pesan atau berkas yang banyak sesuai dengan kata kunci yang ada pada subject.

Sesuai dengan permasalahan yang dikemukakan diatas maka penulis mengangkat judul "Perancangan Mail Client menggunakan mekanisme create folder otomatis".

\section{Landasan Teori}

\subsection{Email}

E-mail merupakan sebuah layanan berupa pesan surat elektronik dengan format tertentu yang diterima dan dikirim melalui jaringan internet dengan aturan tertentu. Dalam proses pengiriman dan penerimaan email terdapat beberapa elemen yang sangat berpengaruh terhadap proses tersebut [2].

\subsection{Mail Client}

Software yang digunakan untuk mengirim dan menerima email melalui komputer tanpa browser. Cukup dengan menjalankan software mail client secara otomatis email akan ter-download ke komputer. Saat tidak terkoneksi dengan internet akan tetap dapat membaca email yang terdownload. [2].

\subsection{Protokol}

Protokol adalah sebuah aturan atau standar yang mengatur atau mengijinkan terjadinya hubungan, komunikasi dan perpindahan data antara dua atau lebih titik komputer. Protokol dapat diterapkan pada perangkat keras, perangkat lunak atau kombinasi dari keduanya. Pada tingkatan yang terendah, protokol mendefinisikan koneksi perangkat keras. Prinsip dalam membuat protokol ada tiga hal yang harus dipertimbangkan, yaitu efektivitas, kehandalan dan kemampuan dalam kondisi gagal di network. Protokol distandarisasi oleh beberapa organisasi yaitu IETF, ETSI, ITU, dan ANSI.

\subsection{SMTP}

SMTP adalah untuk mengirim mail secara efesien dan efektif. SMTP adalah subsistem yang umum dan menginginkan kanal data stream yang teratur dan standar. Secara default SMTP bekerja pada port 25 untuk mengirim email ke server [3]..

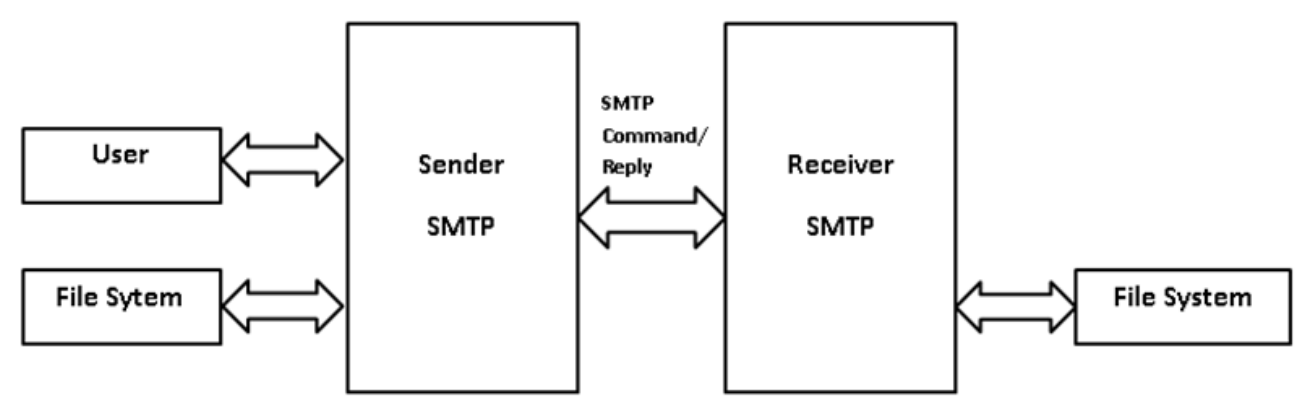

Gambar 1. Model Sistem SMTP

\subsection{TCP}

TCP adalah sekumpulan protokol yang terdapat di dalam jaringan komputer (network) yang digunakan untuk berkomunikasi atau bertukar data dengan komputer. TCP (Transmission Control Protocol) merupakan standar protokol pada jaringan internet yang menghubungkan banyak komputer yang berbeda jenis mesin atau sistem operasi agar dapat berinteraksi satu sama lain. Dalam arsitektur TCP mempunyai 5 lapisan seperti pada Gambar 2. 


\begin{tabular}{|c|}
\hline Application Layer \\
\hline Transport Layer \\
\hline Internet Layer \\
\hline Network Access Layer \\
\hline$\Uparrow \downarrow$ \\
\hline Physical Layer
\end{tabular}

Gambar 2. Arsitektur TCP

\subsection{POP3}

Post Office Protocol Version 3 (POP3) dimaksudkan untuk mengijinkan sebuah workstation secara dinamis mengkases maildrop pada server. Secara umum, POP3 dipakai untuk mengijinkan sebuah workstation untuk mendapatkan mail yang tersimpan dalam server mail. Secara default POP bekerja pada port 110 untuk mengakses mailbox [4].

\section{7. $\quad$ EML}

Berkas EML adalah format berkas yang dikembangkan oleh Microsoft untuk Outlook Express. Berkas EML surel (email) yang diarsipkan yang mempertahankan format dan tajuk (HTML) aslinya. Hampir semua klien surel (email) mendukung berkas EML. Pada dasarnya adalah surel (email) dalam bentuk berkas. Cara termudah untuk membuka adalah dengan menggunakan client surel (email) seperti Outlook, Outlook Express, Windows Live Mail, atau Thunderbird.

\subsection{UML}

Pada perkembangan teknologi perangkat lunak, diperlukan adanya bahasa yang digunakan untuk memodelkan perangkat lunak yang akan dibuat dan perlu adanya standarisasi di berbagai negara dapat mengerti pemodelan perangkat lunak. Banyak yang telah membuat bahasa pemodelan pembangunan perangkat lunak sesuai dengan teknologi pemrograman yang berkembang pada saat itu, misalnya yang sempat berkembang dan digunakan oleh banyak pihak adalah Data Flow Diagram (DFD) untuk memodelkan perangkat lunak yang menggunakan pemrograman prosedural atau struktural.

Pada perkembangan teknik pemrograman berorientasi objek, munculah sebuah standarisasi bahasa pemodelan untuk pembangunan perangkat lunak yang dibangun dengan menggunakan teknik pemrograman berorientasi objek, yaitu Unified Modeling Language (UML). UML merupakan bahasa visual untuk pemodelan dan komunikasi mengenai sebuah sistem dengan menggunakan diagram dan teks-teks pendukung. UML hanya berfungsi untuk melakukan pemodelan.[5]. Jadi penggunaan UML tidak terbatas pada metodologi tertentu, meskipun pada kenyataannya UML paling banyak digunakan pada metodologi berorientasi objek.

\section{Analisa dan Perancangan Sistem}

\subsection{Kebutuhan Sistem}

Dalam melakukan pembuatan aplikasi mail client, ada yang harus dilakukan terlebih dahulu adalah proses perancangan sistem. Hal ini dimaksudkan untuk mempermudah proses pembuatan perangkat lunak menjadi lebih terstruktur. Analisis dan perancangan sistem dimulai dengan analisis kebutuhan perangkat lunak maupun perangkat keras, dan deskripsi perangkat lunak.

\subsubsection{Kebutuhan Hardware}

Perangkat keras dibutuhkan agar dengan efesien dapat menjalankan perangkat lunak dengan baik. Perangkat keras yang digunakan untuk membuat aplikasi adalah :

1. Processor intel(R) Celeron(R) CPU N280 @ 2.16GHz 2.16GHz,

2. RAM $2.00 \mathrm{~GB}$, 
3. Mouse

4. Keyborad

\subsubsection{Kebutuhan Software}

Perangkat Lunak (software) merupakan salah satu komponen penting untuk membantu pembuatan sistem. Jenis-jenis software atau perangkat lunak yang dibutuhkan untuk membantu proses pembuatan aplikasi adalah :

1. Sistem Operasi Komputer (Windows 7 Ultimate)

2. NetBeans 8.0.2

3. Java 1.8.0.20

4. Javamail 1.4.5

5. Wifi

6. Gmail

\subsubsection{Kebutuhan Brainware}

Kebutuhan aplikasi mail client yang penting untuk pengguna dalam mengakses aplikasi mail client adalah sebagai berikut;

1. Mempunyai akun Gmail

2. Menguasai atau memahami penggunaan aplikasi mail client

\subsection{Use Case Diagram Mail Client}

Use case diagram menggambarkan fungsional yang diharapkan dari sebuah sistem. Sebuah use case mempresentasikan interaksi antara actor dengan sistem. Pada Gambar 3 perancangan use case mail client.

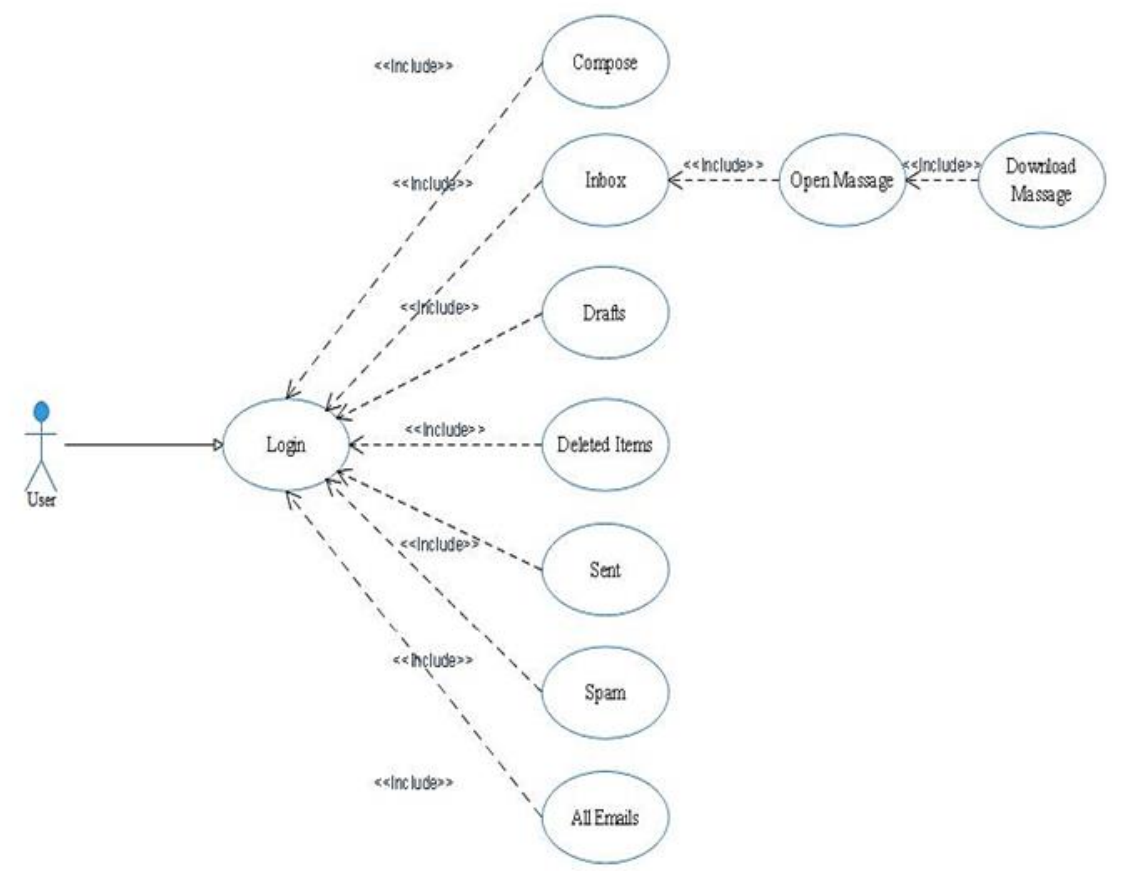

Gambar 3. Perancangan Use Case Diagram Mail Client 


\subsection{Sequence Diagram Mail Client}

Sequence diagram pada aplikasi mail client yang terdapat pada Gambar 4.

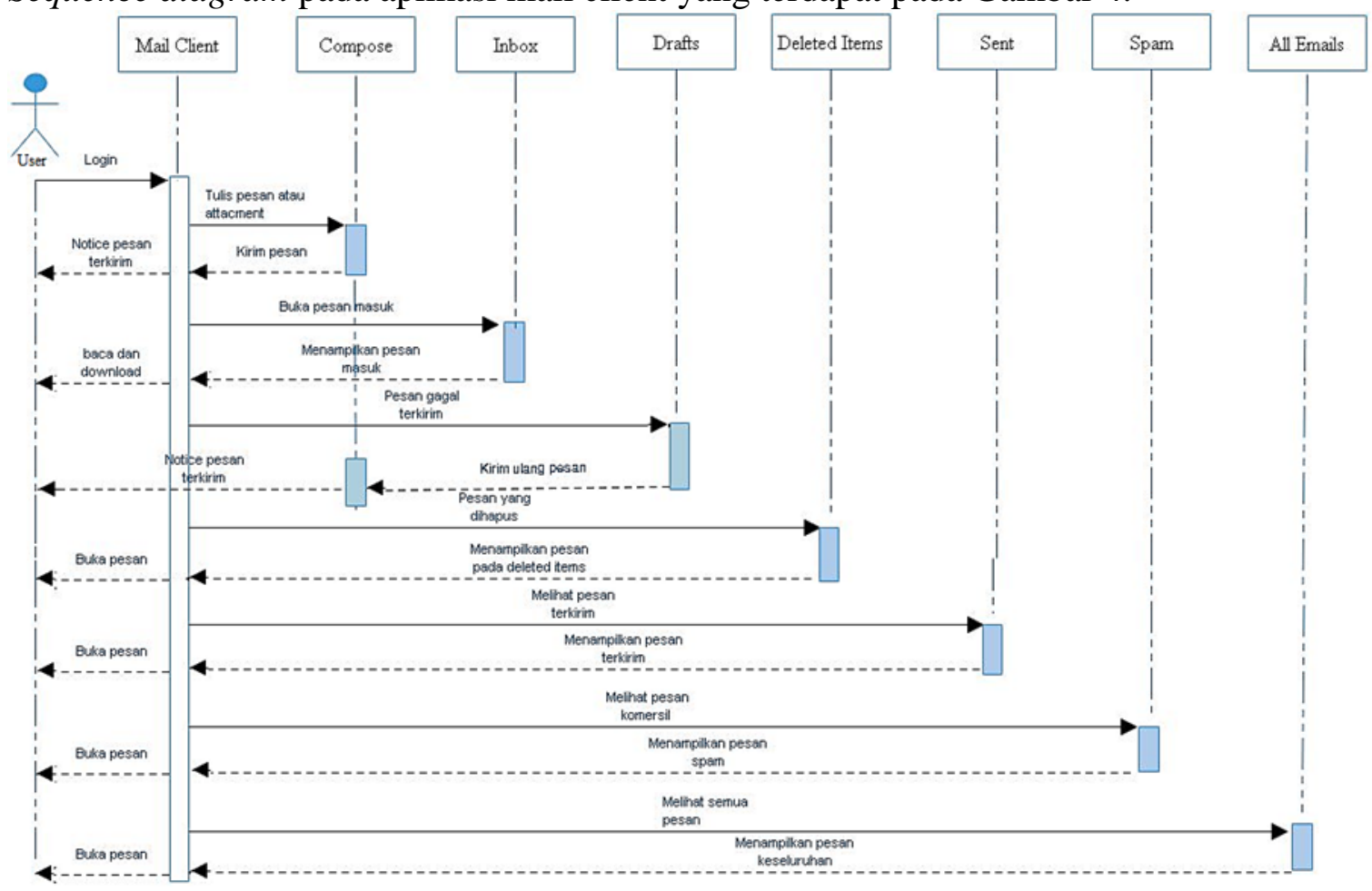

Gambar 4. Sequence Diagram Mail Client

\subsubsection{Sequence Diagram Create Folder Otomatis}

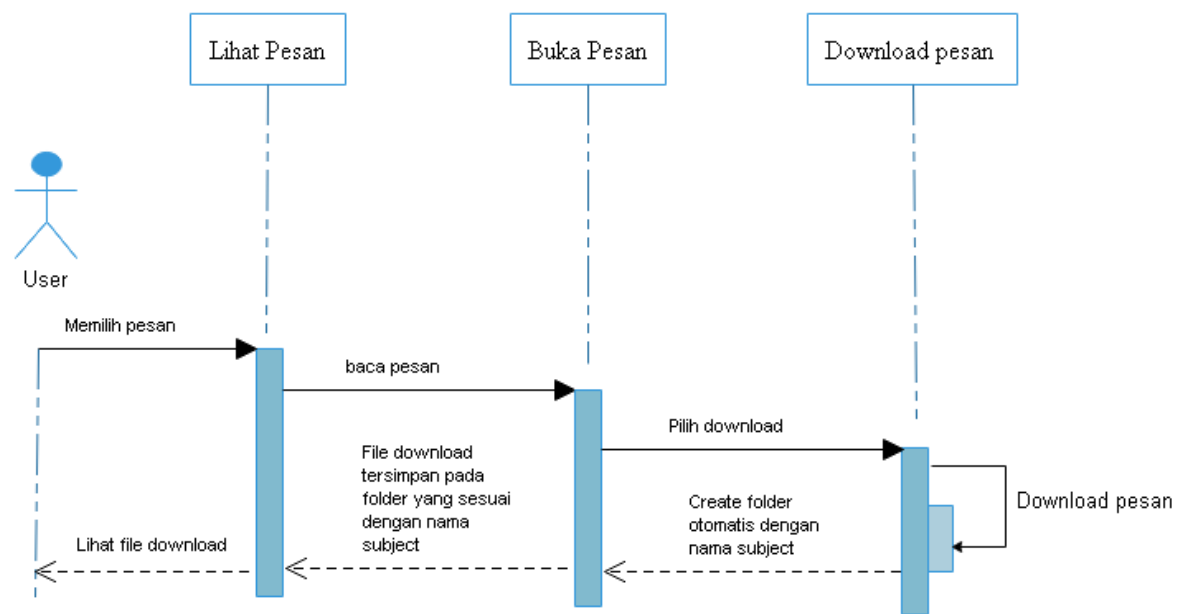

Gambar 5. Sequence Diagram Create Folder Otomatis

Pada Gambar 5 Sequence Diagram Create Folder Otomatis dijelaskan bahwa proses create folder otomatis dimulai dari user memilih pesan kemudian sistem akan membaca pesan yang diingikan $u$ ser. 


\subsection{Activity Diagram Create Folder Otomatis}

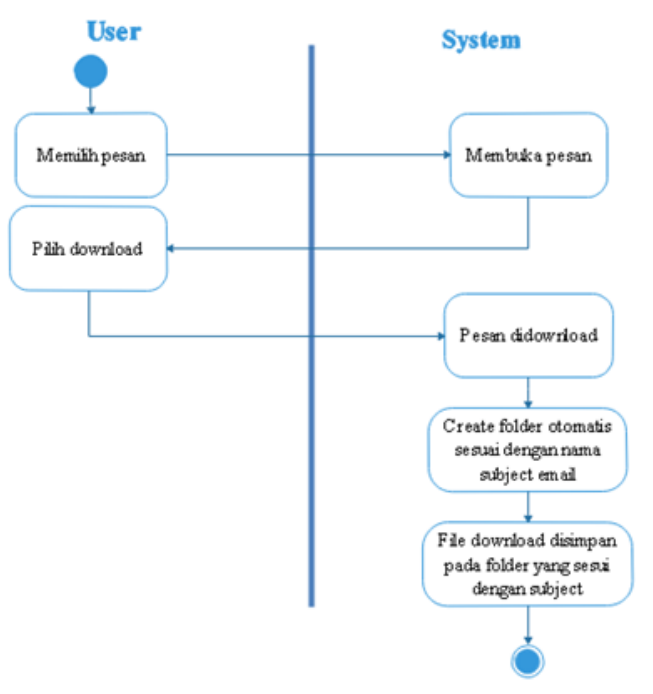

Gambar 6. Activity Diagram Create Folder Otomatis

Pada Gambar 6 Activity Diagram Create Folder Otomatis dijelaskan bahwa proses create folder otomatis dimulai dari memilih pesan kemudian sistem akan membuka pesan yang diinginkan user. Setelah pesan terbuka user memilih download agar sistem men-download pesan tersebut, setelah file sudah ter-downlod maka secara otomatis akan membuat folder sesuai dengan nama subject email. Kemudian file telah ter-download akan tersimpan pada folder otomatis yang telah dibuat oleh sistem. Kemudian user dapat melihat file download tersebut. 


\subsection{Class Diagram Mail Client}

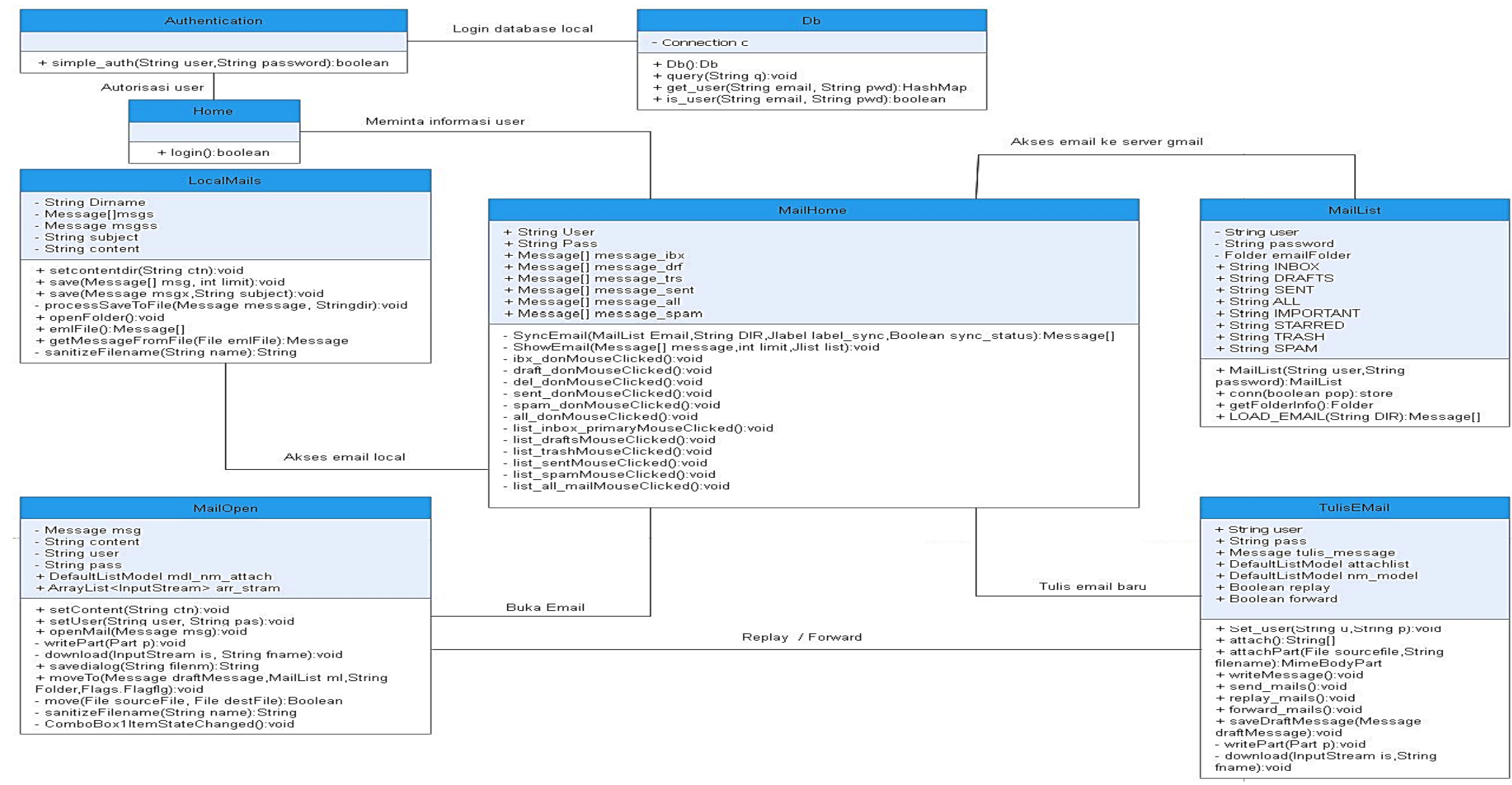

Gambar 7. Class Diagram Mail Client 


\section{Hasil dan Pembahasan}

\subsection{Hasil Implementasi Mail Client}

Pada implementasi aplikasi Mail Client ini akan dijelaskan tentang fungsi dari form yang terdapat pada aplikasi Mail Client. Pada saat aplikasi Mail Client dijalankan maka tampilan awal yang ditampilkan adalah form login, user harus menginputkan username dan password. Username dan password yang digunakan adalah email Gmail. Untuk login pertama kali harus terkoneksi internet. Jika email tidak dapat login dengan pesan AUTH maka harus membuka email melalui web browser dan membuka pesan masuk dari google untuk melakukan ijin akses secara low securel keamanan minimal. Setelah login berhasil maka user bisa mengakses semua fitur yang ada pada aplikasi mail client. Fitur-fitur pada aplikasi mail client yaitu compose, inbox, drafts, sent, deleted emails, spam, dan all emails. User dapat melakukan download pesan, replay pesan, forward pesan, select action pesan, dan delete pesan. Khusus untuk pada fitur inbox dapat melakukan download pesan attachment, data yang di-download akan melakukan pengklasifikasian email secara otomatis berdasarkan subject, untuk pesan atau berkas yang masuk pada email tersebut kemudian akan diunduh dan data yang akan diunduh disimpan pada folder yang sesuai dengan nama subject pesan atau berkas tersebut.

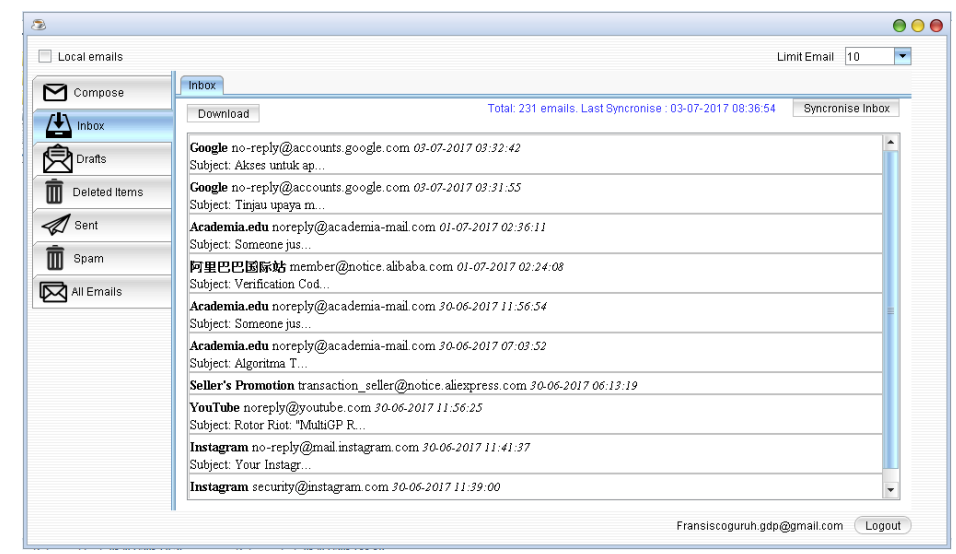

Gambar 8. Form Aplikasi Mail Client

Data atau attachment yang tersimpan berekstensi Eml file seperti pada Gambar 8, jika ingin membuka file attachment tersebut dapat menggunakan aplikasi Mail Client seperti Microsoft Outlook dan Thunderbird, jika tidak memiliki aplikasi tersebut dapat mebuka dengan Base64encode secara online yaitu dengan cara upload file Eml tersebut maka file attachment akan dapat dilihat.

\subsection{Pembahasan}

Dari pengujian untuk aplikasi Mail Client Microsoft Outlook dan Thunderbird dapat dibandingkan dengan aplikasi dari rancangan tugas akhir ini yang secara detail dapat dilihat pada Tabel 1.

Tabel 1. Pengujian 2 Aplikasi Mail Client

\begin{tabular}{|l|l|l|}
\hline \multicolumn{1}{|c|}{ APLIKASIKU } & \multicolumn{1}{c|}{ OUTLOOK } & \multicolumn{1}{c|}{ THUNDERBIRD } \\
\hline Lisensi = Free & Lisensi = Berbayar & Lisensi = Free \\
\hline Fitur = Kurang & Fitur = Lengkap & Fitur = Sedang \\
\hline Desain = cukup & Desain = Baik & Desain = Cukup \\
\hline Halaman HTML= tidak & Halaman HTML= Ya & Halaman HTML=Ya \\
\hline $\begin{array}{l}\text { Engkripsi email download }= \\
\text { tidak }\end{array}$ & $\begin{array}{l}\text { Engkripsi email download }= \\
\text { Ya }\end{array}$ & $\begin{array}{l}\text { Engkripsi email download } \\
\text { Tidak }\end{array}$ \\
\hline
\end{tabular}

Tabel 1. Lanjutan 


\begin{tabular}{|l|l|l|}
\hline \multicolumn{1}{|c|}{ APLIKASIKU } & \multicolumn{1}{c|}{ OUTLOOK } & \multicolumn{1}{c|}{ THUNDERBIRD } \\
\hline $\begin{array}{l}\text { Tipe penyimpanan default }= \\
\text { tidak }\end{array}$ & $\begin{array}{l}\text { Tipe penyimpanan default }= \\
\text { OST }\end{array}$ & $\begin{array}{l}\text { Tipe penyimpanan default }= \\
\text { Tidak }\end{array}$ \\
\hline Gmail $=$ Ya & Gmail $=$ Ya & Gmail= Ya \\
\hline Yahoo $=$ tidak & Yahoo $=$ Ya & Yahoo=Ya \\
\hline Less secure $=$ Ya & Less secure $=$ Ya & Less Secure $=$ Ya \\
\hline
\end{tabular}

Data pada Tabel 1 memperlihatkan bahwa Aplikasiku yang merupakan perangkat lunak hasil dari tugas akhir ini, memiliki kelebihan dan kelemahan terhadap aplikasi pembandingnya yaitu Outlook dan Thunderbird. Kelebihan Outlook dan Thunderbird dibandingkan dengan Aplikasiku antara lain dari sisi fitur, desain, dan enkripsi email, hal ini disebabkan karena aplikasi Outlook bersifat berbayar sehingga pengembangannya baik dari sisi fungsi dan desain dari tahun ke tahun semakin baik.

\section{Penutup}

\subsection{Kesimpulan}

Dari pelaksanaan uji coba didapatkan kesimpulan sebagai berikut;

1. Aplikasi mail client yang dibangun terintegrasi dengan aplikasi Gmail, sehingga data yang ada pada aplikasi mail client dan aplikasi Gmail mempunyai data yang sama atau sinkron.

2. File yang di-download tersimpan pada folder yang sesuai dengan nama subject.

3. Aplikasi mail client dapat membuat folder secara otomatis pada saat men-download pesan.

4. File yang di-download berekstensi *.eml, file tersebut dapat dibuka melalui aplikasi mail client.

5. Aplikasi mail client dapat berjalan pada sistem operasi windows dan linux.

\section{Daftar Pustaka}

[1] Moses, Christian 2013. Perancangan Email Client dengan Pengklasifikasian menggunakan Algoritma Vector Space Model". http://repository.usu.ac.id/bitstream/handle/123456789/45916/Cover.pdf;jsessionid=9C4 F01EA5CBC090E14B7315B288C5687? sequence $=7$.Diakses pada hari senin tanggal 8 Mei 2017.

[2] Lamb (1999). Electronic Mail. www.geocities.ws/bimosaurus/modul/Email.doc. Diakses pada hari kamis tanggal 11 Mei 2017

[3] Khasanah, Nuratri Uswantun 2012. Analisis dan Perancangan Aplikasi Desktop E-Mail Client Menggunakan J2SE. http://repository.amikom.ac.id/files/Publikasi_08.11.2470.pdf. Diakses pada hari rabu tanggal 03 Mei 2017.

[4] I Made, Adi Mahardika 2012. Perancangan POP3 Server dengan Stream Control Transmission Protocol (SCTP) dalam Proses Pengunduhan Email. https://ojs.unud.ac.id/index.php/JLK/article/view/4901. Diakses pada hari rabu tanggal 10 Mei 2017. 
[5] Denis, Alan(2012). System Analys \& Design With UML Version 2.0: Fourth Edistion.Wiley Global Education. 